\title{
Bond slip model in cylindrical reinforced concrete elements confined with stirrups
}

\author{
Simona Coccia $^{1} \cdot$ Erica Di Maggio $^{1} \cdot$ Zila Rinaldi $^{1}$
}

Received: 19 January 2015 / Accepted: 26 September 2015/Published online: 30 October 2015

(c) The Author(s) 2015. This article is published with open access at Springerlink.com

\begin{abstract}
An analytical model able to evaluate the bondslip law of confined reinforced concrete elements is developed and presented in this paper. The model is based on the studies developed by Tepfers and by den Uijl and Bigaj on the thick-walled cylinder model and extended to the case of the presence of transverse reinforcement. The bond strength and the considered failure modes (splitting or pull-out failure) are expressed as a function of the geometrical (concrete cover and transverse reinforcement) and mechanical (concrete strength) parameters of the element. The application of the proposed methodology allows to forecast the failure mode, and equations for the bond-slip law are finally proposed for a range of steel strain lower than the yielding one.
\end{abstract}

Keywords Bond-slip law - Reinforced concrete element with stirrups - Analytical model

\section{List of symbols}

$\sigma_{r, r_{i}} \quad$ Radial stress component on the cylinder at radius $r_{i}$

$\sigma_{t, r_{i}} \quad$ Circumferential stress component on the cylinder at radius $r_{i}$

$\sigma_{r, \mathrm{st}} \quad$ Radial stress on the stirrups

$\sigma_{t, \mathrm{st}} \quad$ Axial stress in the stirrups

$\phi_{\text {st }} \quad$ Stirrup diameter

$\phi_{\mathrm{eq}} \quad$ Equivalent stirrup diameter

$\phi_{b} \quad$ Longitudinal rebar diameter

c Rebar concrete cover

$c_{1} \quad$ Cylinder radius

$r_{s} \quad$ Rebar radius

Simona Coccia

coccia@ing.uniroma2.it

1 Department of Civil Engineering, University of Rome "Tor Vergata", Rome, Italy $r_{\mathrm{cr}} \quad$ Radius of the cracked part of the cylinder

$u_{r, r_{i}} \quad$ Radial displacement at radius $r_{i}$

$p_{\text {st }} \quad$ Stirrups spacing

$\rho_{\mathrm{cc}} \quad$ Ratio between longitudinal reinforcement area and core section area

$\rho_{s} \quad$ Ratio of the volume of transverse confining steel to the volume of confined concrete core

$\varepsilon_{r, r_{i}} \quad$ Radial strain at radius $r_{i}$

$v_{c} \quad$ Concrete Poisson coefficient

$f_{\mathrm{ct}} \quad$ Concrete peak tensile strength

$f_{\mathrm{cm}} \quad$ Mean compressive strength of the concrete

$w_{r} \quad$ Crack width at radius $r$

$s \quad$ slip

$\tau_{b} \quad$ Bond stress

$\tau_{\max } \quad$ Maximum bond stress

\section{Introduction}

The definition of the bond-slip law in reinforced concrete structures is very important in the context of a correct evaluation of deformability, ductility and crack evolution (opening and spacing). Rehm (1961) experimentally showed that the stress arising at the bar-concrete interface depends on the relative sliding, generated between the bar and the surrounding concrete. The bond failure of the adhesion may occur with the propagation of the splitting cracks through the concrete cover (splitting failure) or with the crisis of the concrete corbels (in compression) between the ribs (pull-out failure). The bond strength and the failure modes generally depend on the effectiveness of the confinement provided by the concrete cover and the distance between the bars (Ferguson et al. 1954; Morita and Kaku 1979) and by the transverse reinforcement (Orangun et al. 1977; Kemp and Wilhelm 1979; Skorogobatov and Edwards 1979; Morita 
and Kaku 1979, Morita and Fujii 1982). The influence of the relative rib area and bar diameter on the local bond behaviour is pointed out in (Metelli and Plizzari 2014). Different authors (Rehm 1961; Eligehausen et al. 1983; Shima et al. 1987; Giuriani et al. 1991; Cairns and Jones 1996; Gambarova and Rosati 1997; Yasojima and Kanakubo 2008) proposed analytical formulations for the bond-slip behavior based on experimental results.

In particular, Yasojima and Kanakubo (2008) conducted pull-out bond tests for obtaining the local bond stress versus slip relationship in specimens with confinement of lateral reinforcement. The test results showed the increase of the maximum bond stress with the increment of the lateral confinement stress, and showed how the slippage at maximum bond stress was influenced by splitting crack width and shape of main reinforcement. Finally, based on the obtained results a relationship between bond stress and slippage in case of confinement of lateral reinforcement was proposed.

Finally, the Model Code 2010 suggests bond-slip relationships distinguishing between pull-out and splitting failure, but in this last case, only, allows accounting for the stirrups presence.

Aim of this paper is the definition of an analytical model that allows the evaluation of the bond-slip relationship in confined reinforced concrete elements for a range of steel strain lower than the yielding one. The main difference of the proposed procedure, with respect to the above cited ones, lies in the possibility of recognizing, through a physical, analytical model, the actual failure mode (splitting of the concrete cover or pull-out of the ribbed bar), accounting for the stirrup presence. In particular, the proposed model extends the studies by Tepfers (1979) and den Uijl and Bigaj (1996), developed for unconfined elements on a thick-walled cylinder and by Coccia et al. (2014) for the evaluation of the corrosion in reinforced concrete elements on the bond strength, introducing the effect of transverse reinforcement. Finally, a formulation of the bond-slip relationship, expressed as a function of the mechanical and geometrical parameters, is obtained through a regression with the ordinary least squares method, based on the analytical outcomes of a parametric survey. The results obtained with the proposed model are compared with the most recent formulations available in the literature and discussed above (Yasojima and Kanakubo 2008; Model Code 2010).

\section{Confinement model}

The effect of the confinement on the bond behavior is described with reference to the thick-walled cylinder model (Fig. 1a) developed by Tepfers (1979) and den Uijl and
Bigaj (1996) for elements without transverse reinforcement. The confinement effect introduced in these models is related to the cover concrete of the ribbed bar, only. In the present approach, the confinement due to transversal reinforcement is considered and it is modeled introducing an external radial compressive stress, hereinafter referred to as $\sigma_{r, \mathrm{st}}$. This last variable is here defined as a function of the geometrical characteristics of the cylinder, of the mechanical properties of the stirrups and of the stress state in the cylinder wall.

The response of the thick-walled cylinder is examined in terms of radial stress (radial component of the bond action) and radial deformation at the interface between the ribbed bar and the concrete. A linear elastic distribution of the radial stresses is assumed, up to the reaching of the concrete tensile strength. At this stage, a certain number of radial cracks forms and the cracked part of the cylinder is characterized by a non-linear behaviour. Therefore, three stages can be considered: the uncracked, the partly cracked and the entirely cracked stages, pointed out, in the following, with the superscripts I, II and III, respectively.

\section{Uncracked stage}

Since in the first uncracked stage a linear elastic behavior of the cylinder is assumed, the equations given by Timoshenko (1976) can be adopted. In particular, the reference element is characterized by the stress boundary conditions related to the internal radial pressure and external stirrups:

$\sigma_{r, r_{\mathrm{i}}}=-\sigma_{r, r_{s}}$

$\sigma_{r, r_{\mathrm{e}}}=-\sigma_{r, \mathrm{st}}$

where the subscripts $r, r_{i}$ and $r, r_{e}$ correspond to the radial component at the interface and at the external radius of the cylinder, respectively, $r_{s}$ is the radius of the ribbed bar, $\sigma_{r, r_{s}}$ is the radial component of the bond stress and $\sigma_{r, \mathrm{st}}$ is the radial confinement caused by the transversal reinforcement.

According to Mariotte's law (Fig. 2), the stress $\sigma_{r \text {,st }}$ is evaluated as:

$\sigma_{r, \mathrm{st}} c_{1} p_{\mathrm{st}}=\sigma_{t, \mathrm{st}} \phi_{\mathrm{eq}}^{2} \quad$ then: $\quad \sigma_{r, \mathrm{st}}=\sigma_{t, \mathrm{st}} \pi \frac{\phi_{\mathrm{st}}^{2}}{4}=\sigma_{t, \mathrm{st}} \frac{\phi_{\mathrm{eq}}}{c_{1}}$

where $\sigma_{t, \text { st }}$ is the axial stress of the stirrups, $\phi_{\text {eq }}$ is the equivalent diameter of the transversal reinforcement, $c_{1}$ is the external radius of the cylinder (Fig. 1a).

The equivalent diameter of stirrups is introduced in order to account for two aspects. Firstly, since the action of the transverse reinforcement is concentrated, it cannot be considered diffused on the entire length of the cylinder between individual stirrups; secondly not the whole 
Fig. 1 Thick-walled cylinder a uncracked stage, b partly cracked stage, $\mathbf{c}$ entirely cracked stage, $\mathbf{d}$ tensile constitutive model for concrete

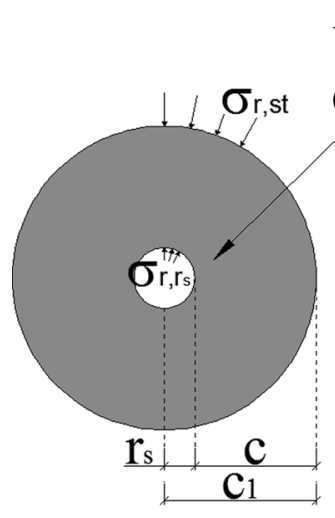

(a) uncracked

concrete cracked

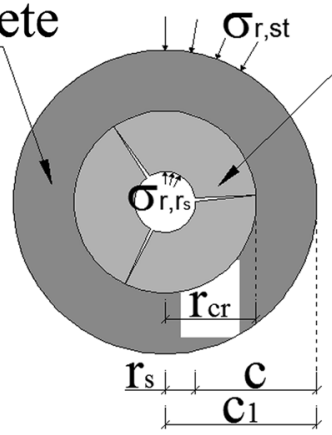

(b) concrete

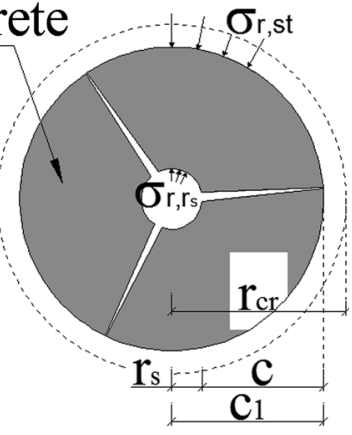

(c)

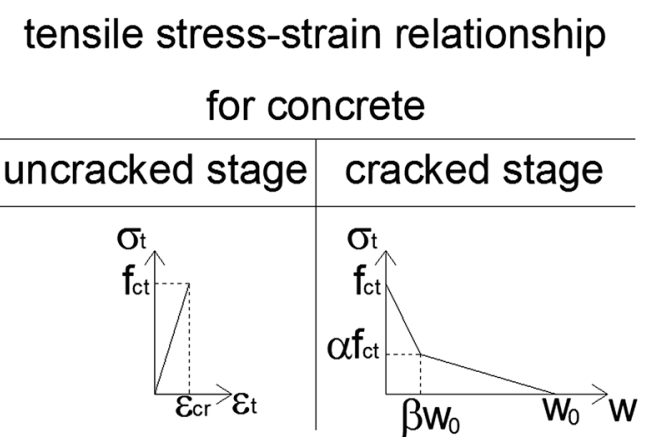

(d)

Fig. 2 a Concrete cylinder confined with stirrups, $\mathbf{b}$ model for Mariotte's law

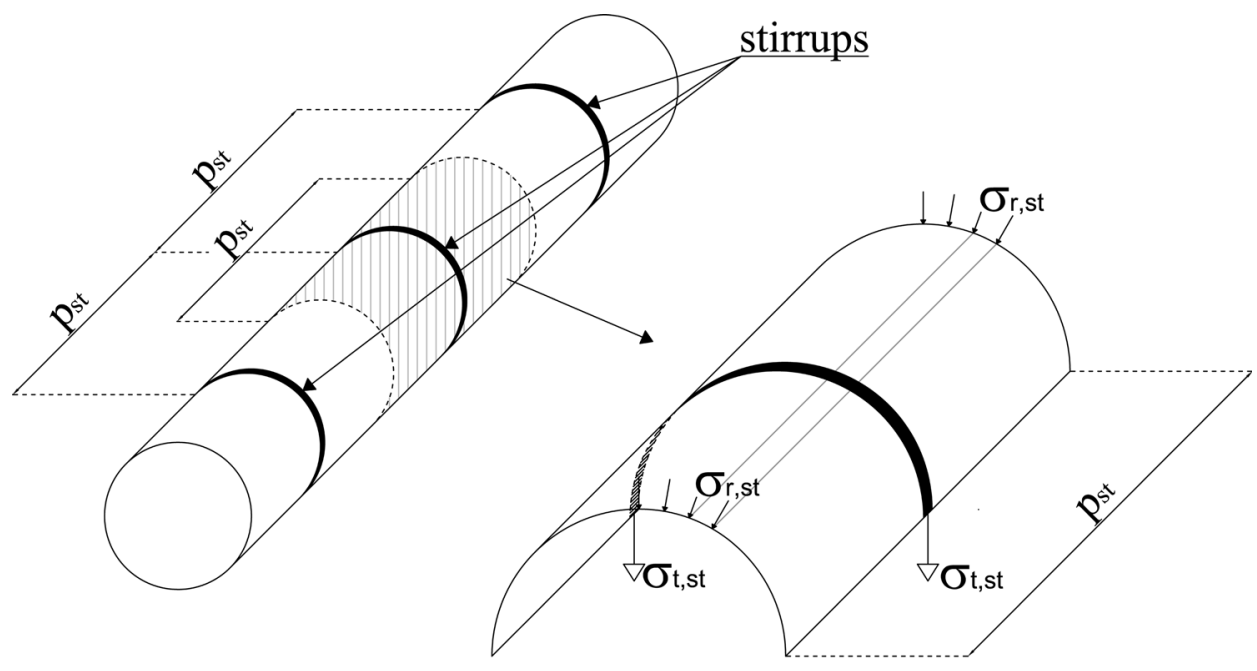

(a)

(b) concrete core is effectively confined by the stirrups. Thus, the equivalent diameter is expressed as:

$\phi_{\mathrm{eq}}^{2}=\phi_{\mathrm{eq}}=k_{\mathrm{eq}} \frac{\phi_{\mathrm{st}}^{2}}{p_{\mathrm{st}}}$

where $\phi_{\mathrm{st}}$ is the diameter of the transverse reinforcement, $p_{\text {st }}$ is the transverse reinforcement spacing, $k_{\text {eq }}$ is the coefficient of efficiency proposed by Mander et al. (1988) that, in the case of the thick-walled cylinder, is equal to:

$k_{\mathrm{eq}}=\left(1-\frac{p_{\mathrm{st}}-\phi_{\mathrm{st}}}{2\left(2 c_{1}-2 c\right)}\right)^{2} \frac{1}{1-\rho_{\mathrm{cc}}}$

being $\rho_{\mathrm{cc}}$ the ratio between the area of longitudinal reinforcement and the area of core section. 
The axial stress of the transversal reinforcement is estimated by the circumferential stress on the cylinder at the external radius, neglecting the minor influence of Poisson effect and assuming an elastic behavior for steel:

$\sigma_{t, \mathrm{st}}=\sigma_{t, r_{e}} \frac{E_{s}}{E_{c}}$

where $\sigma_{t, r_{e}}$ is the circumferential stress at the external radius of the cylinder, $E_{s}$ and $E_{c}$ the Young modulus of steel and concrete, respectively.

Finally, in this stage, the equations given by Timoshenko with the boundary conditions (Eqs. (1) and (2)) in terms of stresses and displacement are:

$\sigma_{r, r}=\sigma_{r, r_{s}} \frac{r_{s}^{2}\left(1+\lambda_{c}\right)}{c_{1}^{2}-r_{s}^{2}+\lambda_{c}\left(c_{1}^{2}+r_{s}^{2}\right)}\left(1-\frac{c_{1}^{2}}{r^{2}}\right)$

$\sigma_{t, r}=\sigma_{r, r_{s}} \frac{r_{s}^{2}\left(1+\lambda_{c}\right)}{c_{1}^{2}-r_{s}^{2}+\lambda_{c}\left(c_{1}^{2}+r_{s}^{2}\right)}\left(1+\frac{c_{1}^{2}}{r^{2}}\right)$

$u_{r, r_{s}}=\frac{\sigma_{r, r_{s}} r_{s}}{E_{c}} \frac{c_{1}^{2}\left(1+\lambda_{c}\right)\left(1+v_{c}\right)+r_{s}^{2}\left(1-\lambda_{c}\right)\left(1-v_{c}\right)}{c_{1}^{2}-r_{s}^{2}+\lambda_{c}\left(c_{1}^{2}+r_{s}^{2}\right)}$

where $\lambda_{c}=\frac{\phi_{\mathrm{eq}}}{c_{1}} \frac{E_{s}}{E_{c}}$ is the coefficient accounting for the confinement effect given by the stirrups.

The radial strain at the interface $\varepsilon_{r, r_{s}}$ is obtained by normalizing the radial displacement $u_{r, r_{s}}$ to the bar radius.

\section{Partly cracked stage}

The uncracked stage ends when the circumferential stress at the interface reaches the tensile strength of the concrete. The fracture criterion, considered both by Tepfers (1979) and den Uijl and Bigaj (1996), is related to a uniaxial state of stress, even if the stress state is evidently biaxial. Talaat and Mosalam (2007) show that the solution accounting for a biaxial failure criterion is not so different from the one related to a uniaxial failure criterion. For this reason, in the proposed approach, the partly cracked stage starts when $\sigma_{t, r_{s}}$ in Eq. (8) is equal to the concrete uniaxial tensile strength $f_{\mathrm{ct}}$. Due to the cracks formation, the cylinder is divided in an internal cracked part and an external uncracked part (Fig. 1b). In the uncracked part the behavior can be considered linear elastic (superscript LE, in the following), while the behavior of the cracked part of the cylinder is non linear (superscript NL, in the following).

As already mentioned, at the crack front $\left(r=r_{\mathrm{cr}}\right)$ the circumferential stress is equal to the tensile strength $f_{\mathrm{ct}}$. Thus, substituting $\sigma_{t, r}=f_{\mathrm{ct}}$ and $r=r_{s}=r_{\mathrm{cr}}$ into Eq. (8) the radial stress at the front crack can be evaluated:

$\sigma_{r, r_{\mathrm{cr}}}=f_{\mathrm{ct}} \frac{c_{1}^{2}-r_{\mathrm{cr}}^{2}+\lambda_{c}\left(c_{1}^{2}+r_{\mathrm{cr}}^{2}\right)}{c_{1}^{2}+r_{\mathrm{cr}}^{2}\left(1+\lambda_{c}\right)}=f_{\mathrm{ct}}\left(C_{1}+\lambda_{c}\right)$ where $C_{1}=\frac{c_{1}^{2}-r_{\mathrm{cr}}^{2}}{c_{1}^{2}+r_{\mathrm{cr}}^{2}}$

Hence, the contribution of the uncracked part of the cylinder at the interface is:

$\sigma_{r, r_{s}}^{\mathrm{LE}}=\frac{r_{\mathrm{cr}}}{r_{s}} \sigma_{r, r_{\mathrm{cr}}}=\frac{r_{\mathrm{cr}}}{r_{s}} f_{\mathrm{ct}} \frac{\left(C_{1}+\lambda_{c}\right)}{\left(1+\lambda_{c}\right)}$

If Eq. (10) is substituted into Eq. (9) and it is assumed $f_{\mathrm{ct}} / E_{c}=\varepsilon_{\mathrm{cr}}$, the radial displacement at the crack front is:

$$
\begin{aligned}
u_{r, r_{\mathrm{cr}}} & =r_{\mathrm{cr}} \varepsilon_{\mathrm{cr}} \frac{c_{1}^{2}\left(1+\lambda_{c}\right)\left(1+v_{c}\right)+r_{\mathrm{cr}}^{2}\left(1-\lambda_{c}\right)\left(1-v_{c}\right)}{c_{1}^{2}+r_{\mathrm{cr}}^{2}} \\
& =r_{\mathrm{cr}} \frac{\varepsilon_{\mathrm{cr}}}{\left(1+\lambda_{c}\right)}\left(1+v_{c} \lambda_{c}+C_{1}\left(v_{c}+\lambda_{c}\right)\right)
\end{aligned}
$$

Thus the radial strain at the interface is:

$\varepsilon_{r, r_{s}}^{\mathrm{LE}}=\frac{r_{\mathrm{cr}}}{r_{s}} \frac{\varepsilon_{\mathrm{cr}}}{\left(1+\lambda_{c}\right)}\left(1+v_{c} \lambda_{c}+C_{1}\left(v_{c}+\lambda_{c}\right)\right)$

The contribution of the cracked part of the cylinder is evaluated by considering the softening behavior of concrete in tension (Fig. 1d). In particular the model of bilinear softening, proposed by Roelfstra and Wittmann (1986) based on Hillerborg's fictitious crack model (1983), is adopted. According to this theory, the fictitious crack width at the generic radius $r$ can be expressed as:

$w_{r}=\frac{w_{0}}{a_{i}}\left(\frac{\sigma_{t, r}}{f_{\mathrm{ct}}}-b_{i}\right)$

where $a_{i}, b_{i}$ and $w_{0}$ are the parameters of the softening model $\quad\left(a_{1}=-(1-\zeta) / \psi, \quad a_{2}=-\zeta /(1-\psi), \quad b_{1}=1\right.$, $\left.b_{2}=\zeta /(1-\psi)\right)$ and $\psi, \zeta$ are the coordinates of the intersection point of the two softening lines (Fig. 1d).

Following the approach proposed by Van der Veen (1990) and neglecting the influence of the radial stress on the circumferential deformation, the total elongation $\Delta_{t, r}$ of a circular fiber with radius $r$ can be expressed as the sum of a rigid radial displacement, giving rise to a constant crack width (Fig. 3a), and an elastic elongation (Fig. 3b):

$\Delta_{t, r}=2 \pi r \varepsilon_{t, r}+n \frac{w_{0}}{a_{i}}\left(\frac{\sigma_{t, r}}{f_{\mathrm{ct}}}-b_{i}\right)$

where $n$ is the number of radial cracks.

At the crack front, where the circumferential stress is equal to $f_{\text {ct }}$, the cracks are closed, therefore the total elongation depends only on the elastic deformation and, neglecting the Poisson effect, it is equal to $2 \pi r_{\mathrm{cr}} \varepsilon_{\mathrm{cr}}$. Substituting into Eq. (15) and solving it:

$\frac{\sigma_{t, r}}{f_{\mathrm{ct}}}=a_{i} \frac{2 \pi \varepsilon_{\mathrm{cr}}}{n w_{0}}\left(r_{\mathrm{cr}}-\frac{\varepsilon_{t, r}}{\varepsilon_{\mathrm{cr}}} r\right)+b_{i}=a_{i} C_{2}\left(r_{\mathrm{cr}}-\frac{\varepsilon_{t, r}}{\varepsilon_{\mathrm{cr}}} r\right)+b_{i}$

where $C_{2}=\frac{2 \pi \varepsilon_{\mathrm{cr}}}{n w_{0}}$. 
Fig. 3 Van der Veen's (1990) steps: a rigid motion, b softening behavior of tensile concrete

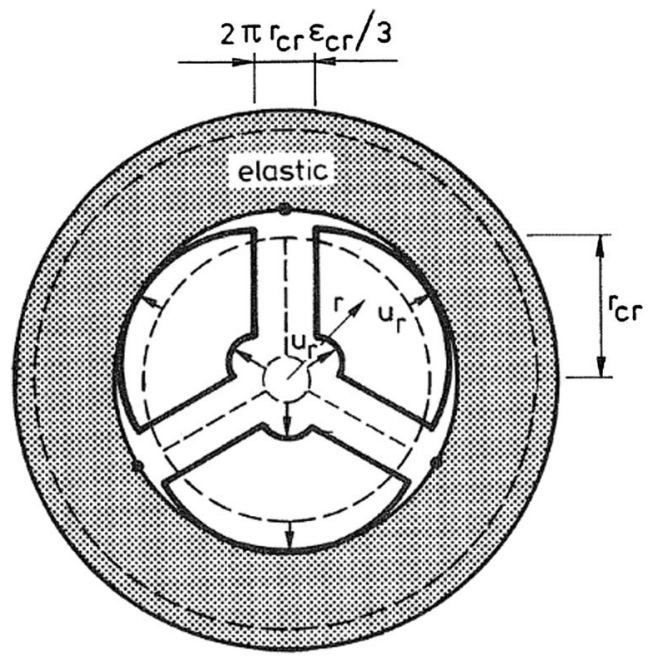

(a)

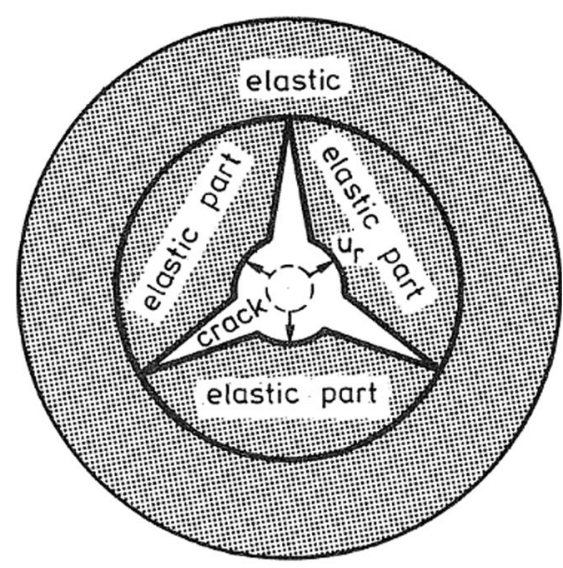

(b)
The radial stress granting the equilibrium of the circumferential state of stress in the cracked part of the cylinder is:

$\sigma_{r, r}^{\mathrm{NL}}=\frac{1}{r} \int_{r}^{r_{c r}} \sigma_{t, r} \mathrm{~d} r$

In order to simplify the solution of Eq. (17), the strain $\varepsilon_{t, r}$ is set equal to $\varepsilon_{\mathrm{cr}}$. This assumption results in an overestimation of the circumferential deformation but, on the other hand, neglecting the Poisson effect results in an underestimation of this quantity. Talaat and Mosalam (2007) showed that these two assumptions balance each other, minimizing the committed error.

The solution of Eq. (17), with the substituting of Eq. (16), allows calculating the radial stress at the interface given by the cracked part of the cylinder:

$\frac{\sigma_{r, r_{s}}^{\mathrm{NL}}}{f_{\mathrm{ct}}}=\frac{a_{i} C_{2} r_{s}}{2}\left(\frac{r_{\mathrm{cr}}}{r_{s}}-1\right)^{2}+b_{i}\left(\frac{r_{\mathrm{cr}}}{r_{s}}-1\right)$

Thus, the total confinement radial stress in the stage II is given by the sum of Eqs. (11) and (18):

$\frac{\sigma_{r, r_{s}}^{\mathrm{II}}}{f_{\mathrm{ct}}}=\frac{\sigma_{r, r_{s}}^{\mathrm{LE}}}{f_{\mathrm{ct}}}+\frac{\sigma_{r, r_{s}}^{\mathrm{NL}}}{f_{\mathrm{ct}}}$

In the evaluation of the radial deformation caused by the cracked part of the cylinder, the Poisson effect is negligible if compared to the effect of the radial cracks. The variation of the wall thickness can be expressed as:

$$
\begin{aligned}
\Delta r_{\mathrm{cr}}^{\mathrm{NL}} & =\int_{r_{s}}^{r_{\mathrm{cr}}} \frac{\sigma_{r, r}^{\mathrm{II}}}{E_{c}} \mathrm{~d} r=\varepsilon_{\mathrm{cr}} \int_{r_{s}}^{r_{\mathrm{cr}}} \frac{\sigma_{r, r}^{\mathrm{LE}}}{f_{\mathrm{ct}}} \mathrm{d} r+\varepsilon_{\mathrm{cr}} \int_{r_{s}}^{r_{c r}} \frac{\sigma_{r, r}^{\mathrm{NL}}}{f_{\mathrm{ct}}} \mathrm{d} r \\
& =\Delta r_{\mathrm{cr}, 1}+\Delta r_{\mathrm{cr}, 2}
\end{aligned}
$$

Solving Eq. (20) the two contributions are:

$$
\begin{aligned}
\Delta r_{\mathrm{cr}, 1}= & \varepsilon_{\mathrm{cr}} r_{\mathrm{cr}}\left(C_{1}+\lambda_{c}\right) \ln \frac{r_{\mathrm{cr}}}{r_{s}} \\
\Delta r_{\mathrm{cr}, 2}= & \frac{\varepsilon_{c r} a_{i} C_{2}}{4}\left(2 r_{\mathrm{cr}}^{2} \ln \frac{r_{\mathrm{cr}}}{r_{s}}-2 r_{\mathrm{cr}}^{2}-r_{s}^{2}+4 r_{\mathrm{cr}} r_{s}\right) \\
& +\varepsilon_{\mathrm{cr}} b_{i}\left(r_{\mathrm{cr}} \ln \frac{r_{\mathrm{cr}}}{r_{s}}-r_{\mathrm{cr}}+r_{s}\right)
\end{aligned}
$$

The radial strain at the interface due to the cracked part of the cylinder is given by:

$\varepsilon_{r, r_{s}}^{\mathrm{NL}}=\frac{\Delta r_{\mathrm{cr}}^{\mathrm{NL}}}{r_{s}}=\frac{\Delta r_{\mathrm{cr}, 1}}{r_{s}}+\frac{\Delta r_{\mathrm{cr}, 2}}{r_{s}}$

Thus, the total radial strain at the interface in the stage II is given by the sum of Eqs. (13) and (23):

$\varepsilon_{r, r_{s}}^{\mathrm{II}}=\varepsilon_{r, r_{s}}^{\mathrm{LE}}+\varepsilon_{r, r_{s}}^{\mathrm{NL}}$

\section{Entirely cracked stage}

The entirely cracked stage starts when the crack front reaches the external radius of the cylinder $r_{\mathrm{cr}}=c_{1}$ (Fig. 1c). The cracks become wider, the confining action of the concrete diminishes due to the softening behavior and the confining action of the transverse reinforcement increases due to its stiffness which contrasts the crack opening.

The circumferential tensile stress is evaluated assuming a constant elongation of the fiber $\Delta_{t, r}=\Delta_{\text {tot }}$ and the circumferential strain $\varepsilon_{t, r}$ is set equal to $\varepsilon_{\mathrm{cr}}$. Rewriting Eq. (15) the circumferential stress is found:

$\frac{\sigma_{t, r}}{f_{\mathrm{ct}}}=a_{i}\left(\frac{\Delta_{\mathrm{tot}}}{n w_{0}}-\frac{2 \pi \varepsilon_{\mathrm{cr}}}{n w_{0}} r\right)+b_{i}=a_{i}\left(C_{3}-C_{2} r\right)+b_{i}$

where $C_{3}=\frac{\Delta_{\mathrm{tot}}}{n w_{0}}$ and $C_{2}$ is defined in Eq. (16). 
The radial stress is given by two contributing factors: the radial stress in the concrete wall which makes equilibrium with the circumferential stress and the radial stress due to the transversal reinforcement:

$\sigma_{r, r}=\frac{1}{r} \int_{r}^{c_{1}} \sigma_{t, r} \mathrm{~d} r+\sigma_{t, \mathrm{st}} \frac{\phi_{\mathrm{eq}}}{c_{1}} \frac{c_{1}}{r}$

where $\sigma_{t, \mathrm{st}}=\frac{\Delta_{\mathrm{tot}}}{2 \pi c_{1}} E_{s}$

Substituting Eq. (25) into Eq. (26) and solving the radial stress at interface is found:

$$
\begin{aligned}
\sigma_{r, r_{s}}^{\mathrm{III}}= & f_{\mathrm{ct}}\left(\frac{c_{1}}{r_{s}}-1\right)\left[a_{i} C_{3}+b_{i}-\frac{a_{i} C_{2} r_{s}}{2}\left(\frac{c_{1}}{r_{s}}+1\right)\right] \\
& +\lambda_{c} E_{c} \frac{\Delta_{\mathrm{tot}}}{2 \pi} \frac{1}{r_{s}}
\end{aligned}
$$

The radial strain at the interface consists in three contributions: the radial strain due to the confining action of the transversal reinforcement at the end of the second stage, the radial deformation due to rigid motion and the radial deformation due to the variation of the wall thickness caused by the radial stress:

$\varepsilon_{r, r_{s}}^{\mathrm{III}}=\varepsilon_{r, c_{1}}^{\mathrm{LE}}+\frac{\Delta_{\mathrm{tot}}-2 \pi c_{1} \varepsilon_{\mathrm{cr}}}{2 \pi r_{s}}+\frac{1}{r_{s}} \int_{r_{s}}^{c_{1}} \frac{\sigma_{r, r_{s}}^{\mathrm{III}}}{E_{c}} \mathrm{~d} r$

Finally, the solution of Eq. (28) gives the radial strain $\varepsilon_{r, r_{s}}^{\mathrm{III}}$ :

$$
\begin{aligned}
\varepsilon_{r, r_{s}}^{\mathrm{III}}= & \varepsilon_{\mathrm{cr}}\left(1+v_{c} \lambda_{c}\right)+\frac{\Delta_{\mathrm{tot}}-2 \pi c_{1} \varepsilon_{\mathrm{cr}}}{2 \pi r_{s}}+\varepsilon_{\mathrm{cr}}\left(a_{i} C_{3}+b_{i}\right) \\
& \times\left(\frac{c_{1}}{r_{s}} \ln \frac{c_{1}}{r_{s}}-\frac{c_{1}}{r_{s}}+1\right) \\
& -\frac{\varepsilon_{\mathrm{cr}} a_{i} C_{2}}{4} r_{s}\left(2\left(\frac{c_{1}}{r_{s}}\right)^{2} \ln \frac{c_{1}}{r_{s}}-\left(\frac{c_{1}}{r_{s}}\right)^{2}+1\right) \\
& +\lambda_{c} \frac{\Delta_{\mathrm{tot}}}{2 \pi r_{s}} \ln \frac{c_{1}}{r_{s}}
\end{aligned}
$$

\section{Bond model}

The bond model is formulated, in agreement with den Uijl and Bigaj (1996), by assuming a boundary layer with a conical surface, in order to skip the problem of local high non-linear stress and strains. The bond mechanism is based on dry friction, thus the bond stress is directly proportional to the radial stress $\sigma_{r, r s}$ :

$\tau_{b}=\sigma_{r, r_{s}} \cot \theta$

where $\cot \theta$ is the friction coefficient.

Splitting failure occurs when the crack front reaches the external face of the cylinder, while when pull-out failure takes place, a cylindrical sliding plain surrounding the ribbed bar forms.

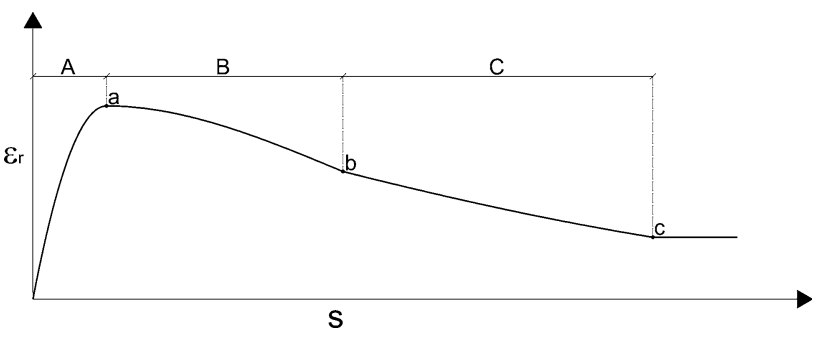

Fig. 4 Radial displacement-slip relationship for pull-out failure (den Uijl and Bigaj 1996)

Table 1 Parameters of radial displacement-slip relationship (Fig. 6) for pull-out failure (den Uijl and Bigaj 1996)

\begin{tabular}{lll}
\hline Point & Deformation & Slip \\
\hline$a$ & $\varepsilon_{r a}$ radial deformation & $\delta_{a}=\frac{\varepsilon_{r a} \phi_{b}}{\tan \varphi}$ \\
& corresponding to & $\varphi=0.1 f_{c}(\mathrm{MPa})$ \\
& $\sigma_{r}=\tau_{b 1}=5 f_{\mathrm{ct}}$ & $\delta_{b}=\frac{\delta_{c}}{2}$ \\
$b$ & $\varepsilon_{r b}=\frac{\varepsilon_{r a}+\varepsilon_{r c}}{2}$ & $\delta_{c}=L_{\mathrm{key}}=0.33 \varphi_{b}$ \\
$c$ & $\varepsilon_{r c}$ radial deformation & $L_{\mathrm{key}}$ length of the concrete \\
& corresponding to & between two subsequent \\
& $\sigma_{r}=\tau_{b 3, \max }=2.5 f_{\mathrm{ct}}$ & ribs \\
& &
\end{tabular}

As proposed by (den Uijl and Bigaj 1996) for the splitting failure the relationship between the radial displacement and the slip $s$ is:

$\varepsilon_{r, r_{s}} r_{s}=s \tan \varphi$

where $\varphi$ is the angle between cone surface and bar axis, assumed equal to $0.1 f_{\mathrm{cm}}$ (den Uijl and Bigaj 1996) with $f_{\mathrm{cm}}$ the mean compressive strength of the concrete.

For the pull-out failure it is considered the relationship proposed by (den Uijl and Bigaj 1996) for steel strains lower than the yielding one. In this case, the radial deformation-slip law simplifies in a piecewise function defined by the points $a, b, c$ and $d$ (Fig. 4) whose coordinates are given in the Table 1. Branches A and B are cubic parabola, branch $\mathrm{C}$ is an exponential function; the point $\mathrm{b}$ is characterized by a horizontal tangent and the point $\mathrm{c}$ is a point of inflection.

The transition from splitting to pull-out failure is identified by the maximum bond stress which must be limited to $5 f_{\text {ct }}$ (den Uijl and Bigaj 1996). When this value is exceeded a pull-out failure occurs.

\section{Analytical results and comparison with existing formulations}

The main results of the proposed model are here reported in the hypothesis of a crack number equal to three, in agreement with den Uijl and Bigaj (1996). 
Figure 5 shows the influence of the transverse reinforcement on the bond behavior in case of splitting failure. The presence of stirrups leads to an increase of the maximum bond stress and an improvement of the softening branch. It is interesting to notice that in the first branch of the curve, which is followed in the case of pull-out failure, there isn't any effect of the transverse reinforcement. This observation is confirmed by the experimental and numerical results of pull-out tests of Torre-Casanova et al. (2013).

The most recent bond-slip relationship is proposed in Model Code 2010 (2012) and allows distinguishing between pull-out and splitting failure, and in this last case, only, allows accounting for the stirrups presence. The Code suggests applying the pull-out curve when there is a good confinement of concrete (concrete cover bigger than $5 \varnothing_{b}$ and distance between the bars bigger than $10 \varnothing_{b}$, with $\varnothing_{b}$ the longitudinal bar diameter) or there is a "suitable confining reinforcement" (MC2010). In Fig. 6a the proposed bond model is compared to the one suggested by Model

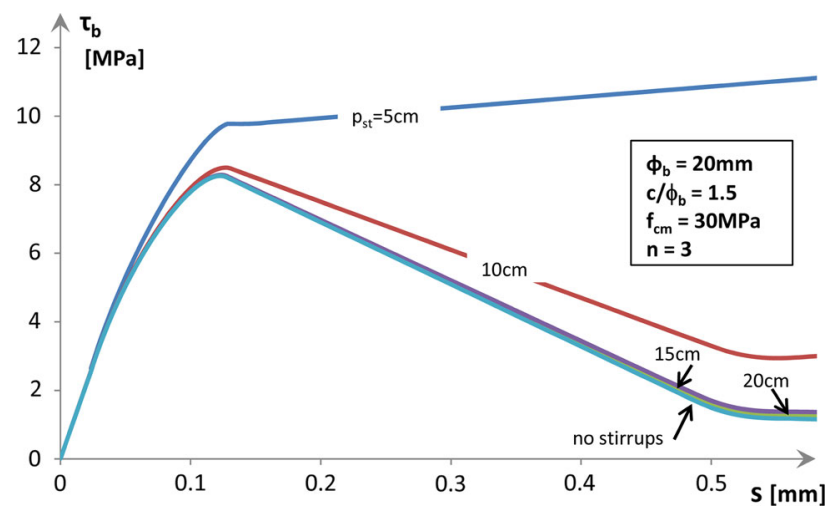

Fig. 5 Influence of the transversal reinforcement on splitting

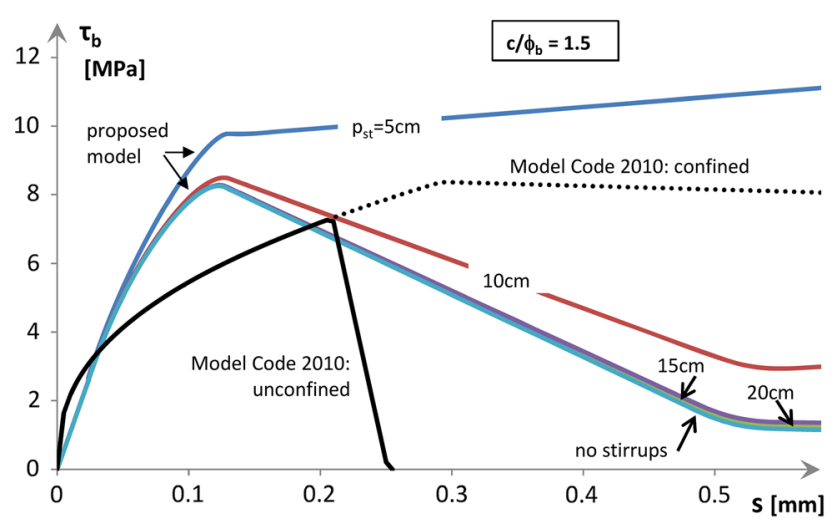

Code 2010 (2012) firstly for pull-out failure, case in which the transverse reinforcement does not play any role in both the models. It appears that the maximum bond strength is comparable, while the slip associated to this value, evaluated with the Model Code prescription, is higher than that estimated with the proposed model. This result was already noted by den Uijl and Bigaj (1996) in comparing some test results with the formulation proposed by Model Code 1990. More significant differences are found for splitting failure (Fig. 6b). In this case, the MC2010 provides two models related to the unconfined and confined behaviour, independently of the stirrups amount. Furthermore, the maximum bond strength depends on the concrete compressive strength only, without any influence of the concrete cover to bar diameter ratio. The MC2010 unconfined model appears to be more conservative, with respect to the proposed one. The maximum bond strength of the MC2010 confined model is similar to the one obtained with the proposed model with a stirrup spacing higher than $100 \mathrm{~mm}$ but the code relationship presents a lower stiffness in the ascending branch.

Yasojima and Kanakubo (2008) proposed a formulation for bond stresses, in case of splitting-failure only, depending on the confining action of the stirrups. In particular, the authors, in order to account for the stirrup presence, add a bond increment $\left(\tau_{b c}\right)$, to the local bond behavior without lateral reinforcement, calibrated on the basis of experimental results from pull-out tests. The bond term $\tau_{b c}$ is a function of the mechanical and geometrical properties of the stirrups, of the slip, of the concrete mechanical properties.

In Fig. 7 their results are compared with the one obtained with the proposed model, for compressive concrete strength $f_{\mathrm{cm}}$ equal to $30 \mathrm{MPa}$, bar diameter

Fig. 6 Comparison between the proposed formulation and the Model Code 2010 one $\left[f_{\mathrm{cm}}=30, \varphi_{b}=20 \mathrm{~mm}\right]$ : splitting failure (a); pull-out failure (b)

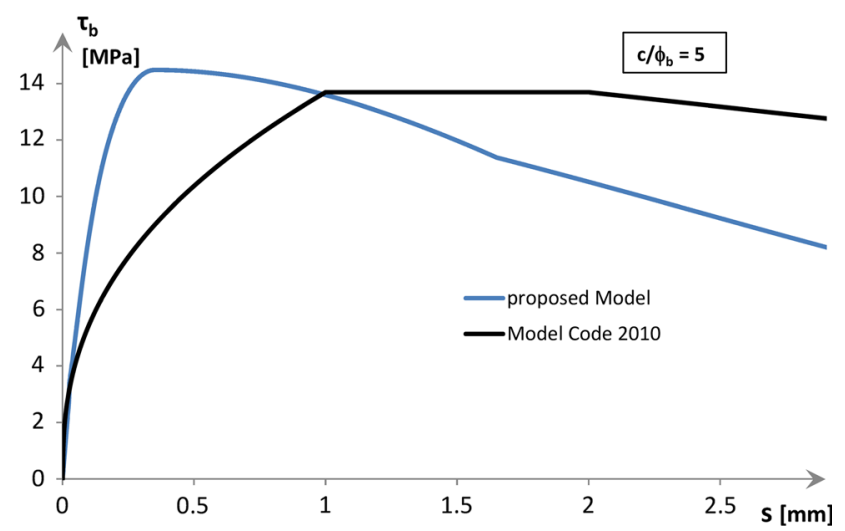



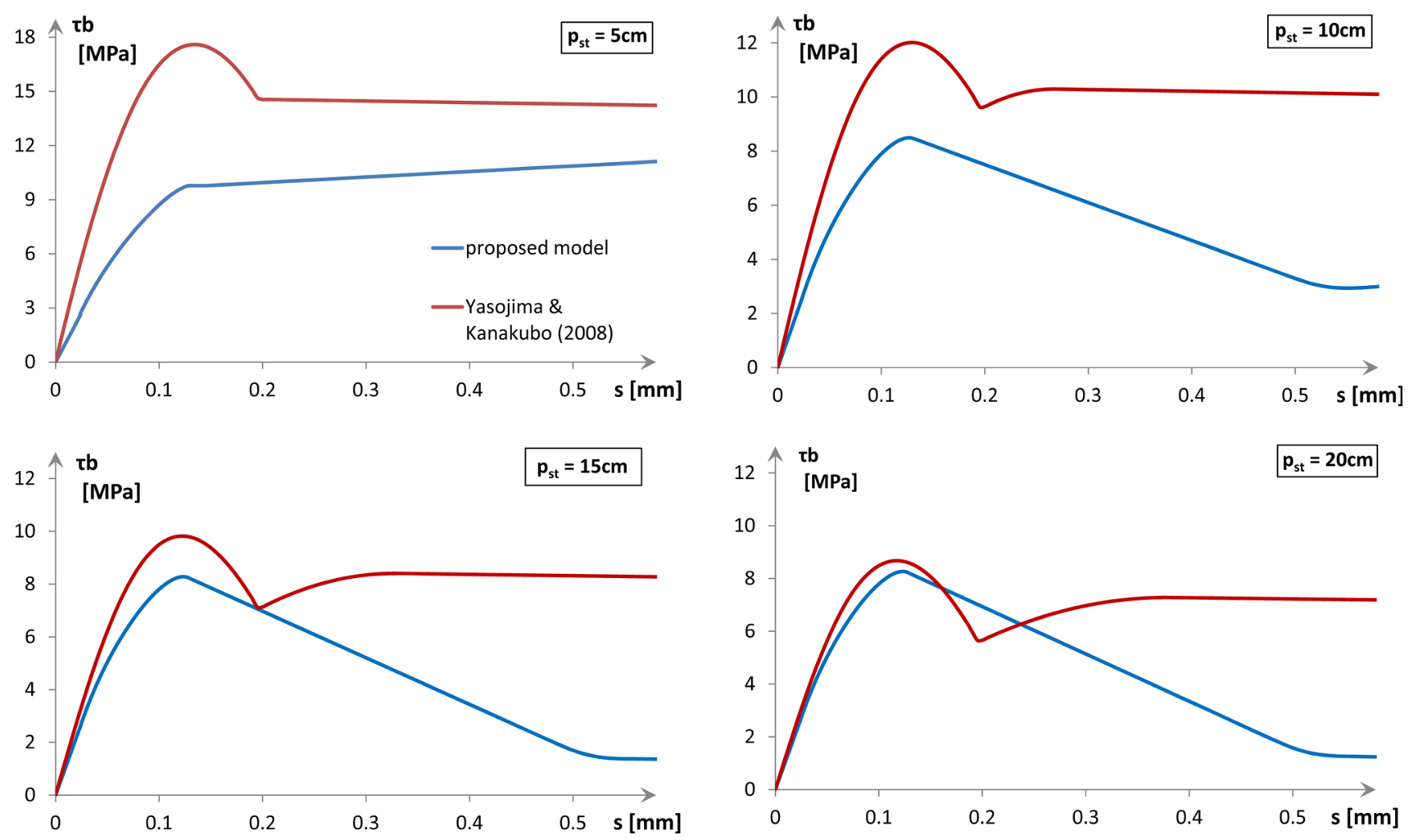

Fig. 7 Comparison between the present formulation and the one proposed by Yasojima and Kanakubo (2008) $\left[f_{\mathrm{cm}}=30 \mathrm{MPa}, \varphi_{b}=20 \mathrm{~mm}, c /\right.$ $\left.\varphi_{b}=1.5\right]$

$\varnothing_{b}=20 \mathrm{~mm}$, and non-dimensional cover ratio $\left(c / \varnothing_{b}\right)$ equal to 1.5. In particular, for stirrups spacing of about $20 \mathrm{~cm}$, the bond stresses, up to the peak value, are very similar. Then, a strange increase of residual bond occurs in the model of Yasojima and Kanakubo. For small stirrups spacing, Yasojima and Kanakubo's solution gives higher peak and residual bond stresses.

\section{Parametric analysis and analytical formulation of the bond-slip model}

Finally, a parametric survey is carried out, in order to highlight the main parameters affecting the bond behaviour. In particular, three variables have been considered and varied, i.e. the concrete compressive strength $\left(f_{\mathrm{cm}}\right)$, the ratio between the concrete cover and the bar diameter $(\mathrm{cl}$ $\varnothing_{b}$ ) and the ratio of the volume of transverse confining steel to the volume of confined concrete core $\left(\rho_{s}\right)$. The first parameter $f_{\mathrm{cm}}$ has been assumed equal to 30,35 and $40 \mathrm{MPa}$; the $\left(c / \varnothing_{b}\right)$ ratio has been set equal to $1.5,2,2.5$ and 3 and the $\rho_{s}$ ratio is supposed equal to $0,1,1.5,2,2.5$ and $3 \%$. All the obtained bond-slip curves can be approximated with three functions defined by the points of coordinates $\left(s_{0} ; \tau_{\max }\right)$ and $\left(s_{1} ; \tau_{r}\right)$ :

$$
\tau_{b}(s)= \begin{cases}\tau_{\max }\left[2 \frac{s}{s_{0}}-\left(\frac{s}{s_{0}}\right)^{2}\right] & 0 \leq s \leq s_{0} \\ \tau_{\max }-\left(\tau_{\max }-\tau_{r}\right) \frac{s-s_{0}}{s_{1}-s_{0}} & s_{0}<s \leq s_{1} \\ \tau_{r} & s>s_{1}\end{cases}
$$

Figure 8 shows the influence of the concrete compressive strength $\left(f_{\mathrm{cm}}\right)$ and non-dimensional cover $\left(c / \varnothing_{b}\right)$ on the values of bond strength $\left(\tau_{\max }, \tau_{r}\right)$ and $\operatorname{slip}\left(s_{0}, s_{1}\right)$ in absence of transverse reinforcement $\left(\rho_{s}=0\right)$. In this case, it can be noted an almost linear variation of the bond strength $\left(\tau_{\max }\right.$, $\left.\tau_{r}\right)$ and slips $\left(s_{0}, s_{1}\right)$ with $f_{\mathrm{cm}}$ and $c / \varnothing_{b}$. In particular $\tau_{\max }$ and $s_{1}$ are highly affected by concrete strength (the first one increases, the last one decreases) with respect to $\tau_{r}$ and $s_{0}$. In particular, this last parameter is almost constant with $f_{\mathrm{cm}}$. The non-dimensional cover ratio influences both strengths and slips that increase with it.

The effect of the stirrups on the bond-slip law is shown in Fig. 9, where the analyzed parameters are plotted as a function of the coefficient $\rho_{s}$, assuming $f_{\mathrm{cm}}=35 \mathrm{MPa}$ and $c / \varnothing_{b}=2.5$. It can be noted the bond stress is influenced by the stirrups only when $\rho_{s}$ exceeds a minimum percentage of transverse reinforcement $\left(\rho_{s, \text { lim }}\right)$. A formulation of $\rho_{s, \text { lim }}$, calibrated on the results of the parametric survey is here proposed as a function of the non dimensional cover $\left(c / \varnothing_{b}\right)$ : 
Fig. 8 Parameters of the proposed bond-slip law in unconfined element

Fig. 9 Influence of the stirrups amount on the parameter of the proposed bond-slip law
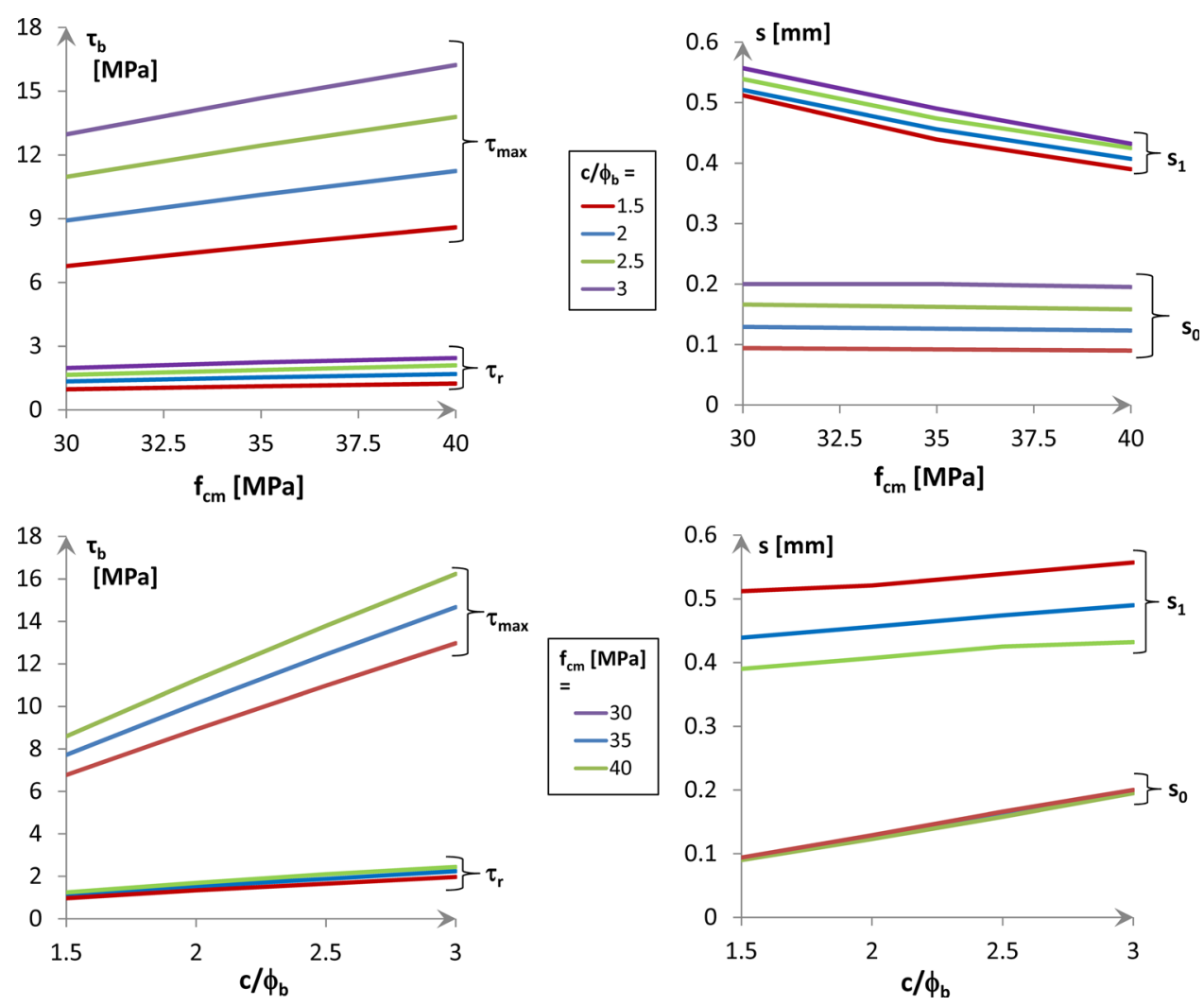

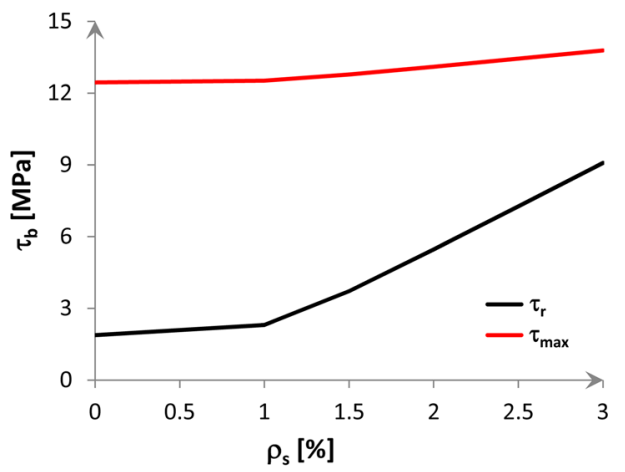

(a)

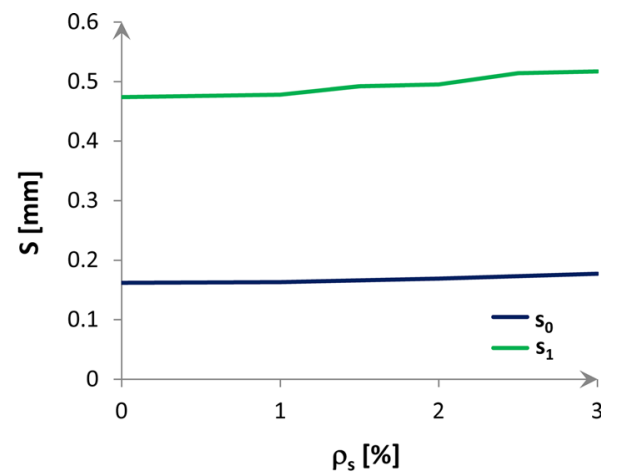

(b) $\rho_{s, \lim }=2.86\left(\frac{c}{\phi_{\mathrm{b}}}\right)^{1.6}$

Moreover, Fig. 9 shows the slips are independent of the stirrups confinement while bond stresses increase with it.

The final result of the parametric analysis is the bondslip law proposed in this paper, whose governing parameters are reported in Table 2 for the splitting or the pull-out failure. The first parabolic branch (Eq. 32) is the same for both the failure modes, but is limited to a maximum bond equal to $5 f_{\mathrm{ct}}$ in the case of pull-out failure (Fig. 10b).
Table 2 Parameters of the proposed bond-slip law

\begin{tabular}{lll}
\hline & Pull-out failure & Splitting failure \\
\hline$\tau_{\max }$ & $5 f_{\mathrm{ct}}^{\mathrm{a}}$ & $\tau_{\max , s}$ (Eq. 34) \\
$\tau_{r}$ & $2.5 f_{\mathrm{ct}}$ & $\tau_{r, s}$ (Eq. 35) \\
$s_{0}$ & $s\left(\tau_{\max }\right)$ & $s_{0, s}$ (Eq. 36) \\
$s_{1}$ & $0.33 \phi_{b}$ & $s_{1, s}$ (Eq. 37) \\
${ }^{\mathrm{a}} f_{\mathrm{ct}}=0.3\left(f_{\mathrm{cm}}-8\right)^{2 / 3}$ &
\end{tabular}




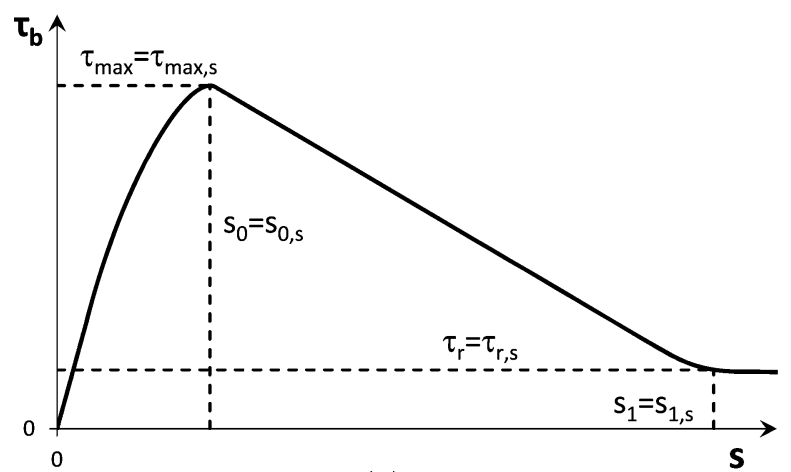

(a)

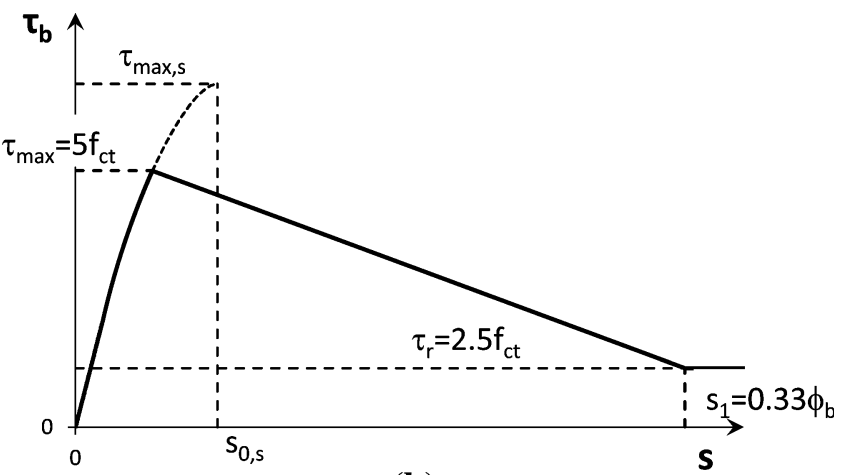

(b)

Fig. 10 Proposed bond-slip law for: a splitting failure; b pull-out failure

The equations of the parameters reported in Table 2 for the splitting bond failure are:

$$
\begin{aligned}
\tau_{\max , s}= & 1.738\left(\frac{c}{\phi_{b}}+0.122\right)\left(f_{\mathrm{ct}}+0.067\right) \\
& \times \begin{cases}1 & \text { if } \rho_{s} \leq \rho_{s, \mathrm{lim}} \\
1+\frac{1.1}{1000}\left(\rho_{s}-\rho_{s, \lim }\right) & \text { if } \rho_{s}>\rho_{s, \mathrm{lim}}\end{cases} \\
\tau_{r, s}= & 0.25\left(\frac{c}{\phi_{b}}-0.025\right)\left(f_{\mathrm{ct}}+0.4\right) \\
& \times \begin{cases}1 & \text { if } \rho_{s} \leq \rho_{s, \mathrm{lim}} \\
e^{\frac{\left(\rho_{s}-\rho_{s, \mathrm{lim})}\right.}{\phi_{\mathrm{cm}} \mathrm{s}}} & \text { if } \rho_{s}>\rho_{s, \mathrm{lim}}\end{cases} \\
s_{0, s}= & \frac{0.35\left(\frac{c}{\phi_{b}}-0.2\right)}{50} \frac{\phi_{b}}{2} \\
s_{1, s}= & \frac{0.0017\left(\frac{c}{\phi_{b}}+14.5\right)}{1000 \tan \left(0.1 f_{\mathrm{cm}}\right)}
\end{aligned}
$$

where $\rho_{s}$ is expressed in percentage (\%), $f_{\mathrm{ct}}$ and $f_{\mathrm{cm}}$ in MPa.

The constant coefficients in Eqs. (34-37) are obtained through a regression with the ordinary least squares method, with reference to the analytical outcomes of the parametric analysis (see Figs. 8, 9).

The concrete cover that corresponds to a change from a splitting failure to a pull-out failure is defined by the authors as:

$$
\left(\frac{c}{\phi_{b}}\right)_{\text {splitting to pull-out }}=\left(2.5+0.007 f_{\mathrm{cm}}\right)\left(1-27 \rho_{s} \frac{f_{\mathrm{sy}}}{f_{\mathrm{cm}}}\right)
$$

always obtained through a regression with the ordinary least squares method $\left(\rho_{s}\right.$ expressed in percentage $(\%)$ and $f_{\mathrm{cm}}$ in MPa).

\section{Conclusions}

A bond model for ribbed bars has been developed using an analytical study of the confining capacity of concrete including the confining action of a transversal reinforcement. The proposed procedure, based on the thick-walled cylinder model, allows considering different type of concrete, ribbed bars, transversal reinforcement and geometry of the element analyzed. Starting from the radial stressstrain $\left(\sigma_{r}-\varepsilon_{r}\right)$ relationship, the bond-slip $\left(\tau_{b}-s\right)$ relationship is developed, distinguishing between the two failure modes of splitting of the concrete cover or pull-out of the ribbed bar. Finally, a formulation of the bond-slip is proposed, that considers, not only the concrete mechanical properties, but takes directly account of the concrete cover ratio $\left(c / \phi_{b}\right)$ and the percentage of transversal reinforcement $\left(\rho_{s}\right)$. The results obtained with the proposed model has been finally compared with the one obtained with some exiting formulations.

Open Access This article is distributed under the terms of the Creative Commons Attribution 4.0 International License (http://crea tivecommons.org/licenses/by/4.0/), which permits unrestricted use, distribution, and reproduction in any medium, provided you give appropriate credit to the original author(s) and the source, provide a link to the Creative Commons license, and indicate if changes were made.

\section{References}

Cairns J, Jones K (1996) An evaluation of the bond-splitting action of ribbed bars. ACI Mater J 93(2):10-19

Coccia S, Imperatore S, Rinaldi Z (2014) Influence of corrosion on the bond strength of steel rebars in concrete. Mater Struct. doi:10.1617/s11527-014-0518-x

den Uijl JA, Bigaj AJ (1996) A bond model for ribbed bars based on concrete confinement. Heron 41(3):201-226 
Eligehausen R, Popov EP, Bertero VV (1983) Local bond stress-slip relationships of deformed bars under generalized excitations. Report No. UCB/EERC 83-23, University of California, Berkeley

Ferguson PM, Turpin RD, Thompson JN (1954) Minimum bar spacing as a function of bond and shear strength. ACI Struct J 50(6):869-887

Gambarova PG, Rosati GP (1997) Bond and splitting in bar pull-out: behavioral laws and concrete cover role. Mag Concr Res 49(179):99-110

Giuriani E, Plizzari GA, Schumm C (1991) Role of stirrups and residual tensile strength of cracked concrete on bond. J Struct Div ASCE 117(1):1-18

Hillerborg A (1983) Analysis of one single crack. In: Wittmann FH (ed) Fracture Mechanics of Concrete, Elsevier, Amsterdam, pp 223-249

Kemp EL, Wilhelm WJ (1979) Investigation of the parameters influencing bond cracking. ACI Struct J 76(1):47-71

Mander JB, Priestley NM, Park R (1988) Theoretical stress-strain model for confined concrete. J Struct Concr 114:1804-1826

Metelli G, Plizzari AG (2014) Influence of the relative rib area on bond behaviour. Mag Concr Res 66(6):277-294

Model Code 2010 (2012), CEB-FIP, Final Draft, Bullettin d'Information n. 65/66

Morita S, Fujii S (1982) Bond capacity of deformed bars due to splitting of surrounding concrete. In: Bartos $\mathrm{P}$ (ed) Bond in concrete. Applied Science Publishers, London, pp 331-341

Morita S, Kaku T (1979) Splitting bond failures of large deformed reinforcing bars. ACI Struct J 76(1):93-110
Orangun CO, Jirsa JO, Breen JE (1977) Re-evaluation of test data on development length and splices. ACI Struct J 74(3):114-122

Rehm G (1961) On the fundamentals of steel-concrete bond. Deutscher Ausschuss für Stahlbeton 138:1-59

Roelfstra PE, Wittmann FH (1986) Numerical method to link strain softening with failure of concrete. In: Fracture toughness and fracture energy of concrete, pp 165-173

Shima H, Chou LL, Okamura H (1987) Bond characteristics in postyield range of deformed bars. Concr Libr JSCE 10:113-124

Skorogobatov SM, Edwards AD (1979) The influence of the geometry of deformed steel bars on their bond strength in concrete. Proc Inst Civil Eng Part 2(67):327-339

Talaat M, Mosalam KM (2007) on bond failure by splitting of concrete cover surrounding anchored bars. Proc., 6th Int. Conf. on Fracture Mechanics of Concrete and Concrete Structures (FraMCoS-6).Taylor \& Francis, London

Tepfers R (1979) Cracking of concrete cover along anchored deformed reinforcing bars. Mag Concr Res 106(31):3-12

Timoshenko S (1976) Strength of materials. Part II, Advanced theory and problems. Van NostrandReinhold, pp. 205-210

Torre-Casanova A, Jason L, Davenne L, Pinelli X (2013) Confinement effect on the steel-concrete bond strength and pull-out failure. Eng Fract Mech 97:92-104

Van der Veen G (1990) Theoretical and experimental determination of crack width in reinforced concrete at very low temperature. HERON 35(2): 1990

Yasojima A, Kanakubo T (2008) Local bond splitting behavior of RC members with lateral reinforcement, Beijing, China. In: 14th World Conference on Earthquake Engineering, Conference Proceedings 